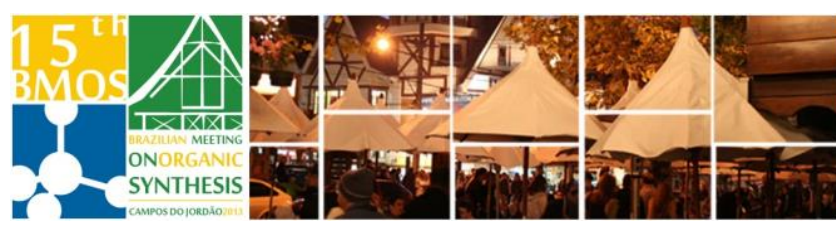

\title{
Peptide and cyclopetide synthesis via Ugi and click reactions under microwave irradiation and in continuous flow system
}

\author{
Carlos Eduardo M. Salvador ${ }^{1}$, José Giovanni L. Brito ${ }^{1}$, Leandro Soter de M. \\ Miranda $^{2}$, Rodrigo O. M. A. Souza ${ }^{2}$, Carlos Kleber Z. Andrade ${ }^{\star 1}$ \\ ${ }^{1}$ Laboratório de Química Metodológica e Orgânica Sintética (LaQMOS), IQ-UNB. \\ ${ }^{2}$ Biocatalysis and Organic Synthesis Group (BOSS Group), IQ-UFRJ.
}

Keywords: Click reaction, continuous flow, Ugi reaction

\section{INTRODUCTION}

Cyclopeptides usually stand out due to their structural characteristics and their physico-chemical and biological properties of interest for use as therapeutic agents. ${ }^{1}$ The increasing use of microreactors as a promising technology for the synthesis of compounds with pharmaceutical application and the absence of reports in the literature investigating the Ugi / Click reactions in cyclopeptide synthesis in continuous flow systems were the major motivations for this work.

\section{RESULTS AND DISCUSSION}

The first step in our approach was the synthesis of an isonitrile attached to an aromatic ring functionalized with a propargyl ether (Scheme 1). The triple bond is needed for the final click reaction with a remote azide group. It is known that functionalized isonitriles do not have the characteristic bad smelling of the isonitriles family and these compounds have been successfully applied in multicomponent reactions. ${ }^{2}$ The synthesis of the odorless isonitrile 6 was performed in four steps with an overall yield of $47 \%$. This new isonitrile was found to be bench stable.

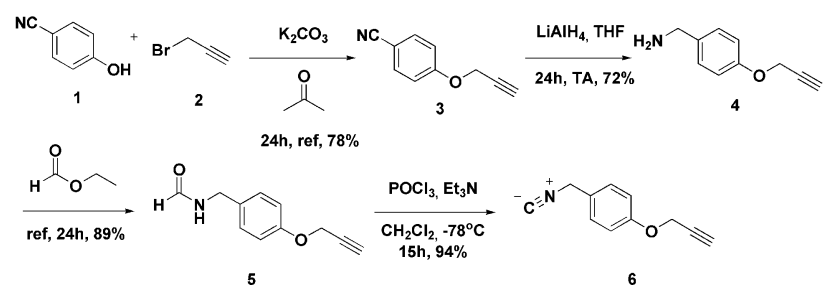

Scheme 1. Synthesis of isonitrile 6.

With the new isonitrile in hand, we set out to test its viability in Ugi reactions. In the presence of benzyl amine, various types of aldehydes and 2-azidoacetic acid, the isonitrile 6 proved to be effective in peptide synthesis (Scheme 2). The Ugi reactions were efficiently carried out under microwave conditions, thus providing several peptides in good yields. A complimentary approach using $p$-formaldehyde, different aliphatic amines and $p$-azinobenzoic acid was also investigated (44-69\% yield of products).

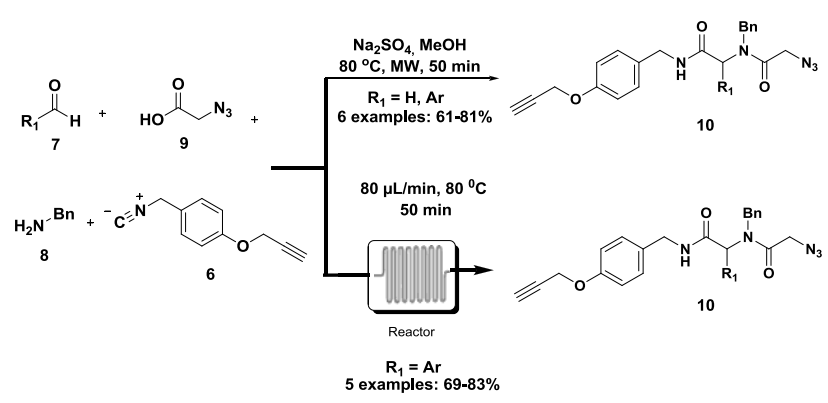

Scheme 2. Ugi reactions under MW and continuous flow conditions.

MW-assisted organic reactions generally behave similarly under continuous flow conditions. ${ }^{3}$ Indeed, under these conditions, the Ugi products were obtained with a small increase in the yields $(10 \%$ in average) compared to the MW conditions (Scheme 2). The next step was an intramolecular click reaction of compound $\mathbf{1 0}$ under microwave irradiation by which the cyclic $N$-alkylated cyclopeptides 11 were obtained in moderate nonoptimized yields (Scheme 3). The click reactions in continuous flow conditions are under investigation.

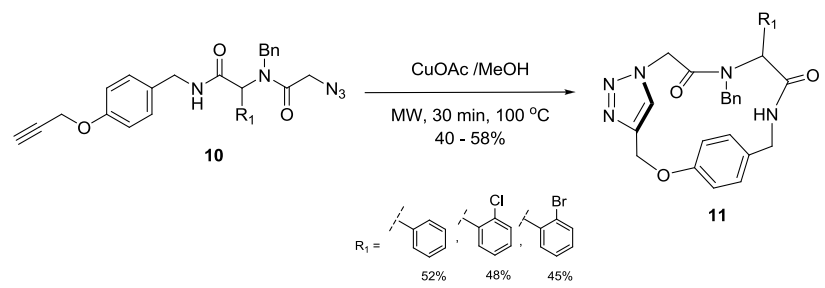

Scheme 3. MW-mediated click reactions.

\section{CONCLUSION}

The use the Ugi and click reactions in continuous flow conditions for the synthesis of cyclopeptides is an important tool for the synthesis of various compounds for pharmaceutical applications.

\section{ACKNOWLEDGEMENTS}

IQ-UnB, CAPES, CNPq and FINEP-CTINFRA nํำ0970/01.

\section{REFERENCES}

1 - Dömling, A.; Chem. Rev. 2006, 106, 17.

2 - Pirrung, M. C.; Ghorai, S.; Ibarra-Rivera, T. R.; J. Org. Chem. 2009, 74, 4110.

3 - Glasnov, T. N.; Kappe, C. O. Chem. Eur. J. 2011, 17, 11956. 